\title{
The learning continuum: economical best practices for implementing and achieving a community's information literacy goals
}

\author{
Shiva Darbandi, Carolyn Waite, Rose Flores Medlock
}

\begin{abstract}
Information literacy is a driving force in the field of librarianship, however, the often underestimated complexity of the concept, the primary focus on academic libraries, the intricacies involved with transliteracies, and the obstacles associated with technology make it difficult to establish a strategy for meeting a community's information literacy needs. Budget cuts have especially impacted public library programming, pushing information literacy goals further out of reach. Faced with this adversity, Lancashire Library Service partnered with Credo to enhance their current information literacy plan, which yielded immediate results and provides a blueprint that public libraries may follow to achieve similar goals.
\end{abstract}

\section{Introduction}

The principles of information literacy embody the ethos of public libraries around the world. While the term lacks a finite definition (Elmborg, 2006; Probert, 2009; Virkus, 2003), information literacy's unification of concepts such as information retrieval and analysis, technological literacy, critical thinking, and lifelong learning closely aligns to the objectives of today's public libraries, which are charged with maintaining free and open access to information despite the challenges of the digital divide. The parallels between information literacy and the purpose of public libraries are clear, however, information literacy has yet to obtain a significant foothold in the public library lexicon (Bawden and Robinson,

\section{Authors}

Shiva Darbandi, MLIS, collaborates with a broad range of libraries to develop and implement information literacy materials, assessments, and promotional campaigns.

Email: shiva.darbandi@credoreference.com

Carolyn Waite is the Information Development Manager at Lancashire County Council and oversees the library programmes impacting information literacy.

Rose Flores Medlock, a professional editor and journalist of 10 years, currently is a candidate for an MLIS degree at the University of Pittsburgh. 
2009; Harding, 2008). For a term coined nearly four decades ago (Collins and Takacs, 1993; Kapitzke, 2003; Zhang, Majid and Foo, 2010), it has continued to remain elusive in the public library sector due to the overwhelming challenges described below. This is in spite of a growing acceptance in school libraries and media centres as well as the academic library sphere (Eisenberg, 2010; Špiranec and Zorica, 2010).

The vitality of information literacy in these realms, along with the concept's close alignment with the institution's goals, were the primary motivating factors for Lancashire Library Service's push towards an in-depth incorporation of an information literacy plan, specifically one that sought to empower staff and community members with the tools necessary to become successful digital citizens in the 21 st century. Their decision to take the steps required to implement such a plan was made viable by the resources and support offered by Credo - a library provider to thousands of academic, school, and public libraries - through an information literacy pilot programme. Having witnessed Lancashire Library Service's commitment to information literacy firsthand through earlier collaborations, Credo selected the institution as one of several libraries to participate in a pilot study to promote the library and all of its resources. Together they developed a framework for an information literacy strategy that can be implemented in public libraries regardless of size, community, resources, and other such pertinent factors.

\section{The information literacy void}

There are several reasons for the disparity between the information literacy focus found in school and academic library settings and the lack thereof in public libraries. Information literacy is a complex concept, making it difficult to dissect and implement in a clear-cut format. Much of the literature on information literacy is mired in an academic rhetoric that is not as easily accessible and relatable to an audience that is far from steeped in the world of academia. Publications about constructivism, authentic assessment, and experiential learning touch on topics that are part of the day-to-day vernacular of academic and school libraries, whereas these concepts rarely are explored in public libraries. The authors posit that article titles such as Jacobs' (2008) 'Information Literacy and Reflective Pedagogical Praxis" alienate public librarians with terminology that is unfamiliar.

Moreover, few articles target public libraries when discussing information literacy. An extensive multinational literature review spanning the course of three decades (1973 and 2002) found that 60 per cent of the publications concerning information literacy concentrated on academic libraries (Rader, 2002). To reiterate, even with the proliferation of access to the web in the early $2000 \mathrm{~s}$, a separate literature review between 2000 and 2005 found that only 2 per cent of library-related English language articles concentrated on information literacy in the public library sector (Demasson, Partridge and Bruce, 2010). Several individuals also argue that the ambiguity of information literacy adds to confusion and ambivalence amongst public librarians who may understand the term as primarily relating to higher education topics in line with bibliographic instruction and advanced research skills (Demasson, Partridge and Bruce, 2010; Elmborg, 2006; Heidi and Hoffman, 2008). 
Further issues arise when the notion of transliteracies is introduced. Transliteracies are defined as:

the ability to read, write and interact across a range of platforms, tools and media from signing and orality through handwriting, print, TV, radio and film, to digital social networks.

(Thomas et al., 2007)

As entities that often consider themselves community centres, public libraries perform the task of providing a variety of information, falling under the umbrella of transliteracies. Computer classes, social media-related questions, and technology petting zoos are not uncommon in the public library space. Libraries offer technology petting zoos to allow patrons opportunities to interact with applications, gadgets, games, or software including e-book readers, digital cameras, smartphones, or tablets (Sze, 2012). In Lancashire's case, e-books and eresources were highlighted during interactive sessions with users. The goal not only was to help patrons become familiar with technology but also to introduce them to a wealth of library resources offered by the library. While these services cover transliteracies, transliteracies are not in and of themselves a substantial substitute for information literacy, although they often may be confused as such. Though there is overlap between the topics covered in transliteracies and information literacy, the former does not evoke the critical thinking skills that make information literacy an important factor in preparing digital citizens for the 21 st century. Addressing these issues piecemeal has the effect of denying what information literacy strives to produce: a user capable of accessing information, as well as evaluating it and using it responsibly.

Academic libraries foster multiple opportunities to teach information literacy skills to students through embedded librarianship, one-shot instructional sessions, and first year seminar classes, however, the task is far more daunting in the public library sector where there generally are fewer computers available. Additionally, attending such sessions is compulsory in academic spheres, whereas public libraries must deal with the added burdens of both promoting and designing information literacy sessions that are relevant and engaging. Further compounding the issue are budget cuts, which have created challenges for public libraries in the UK, USA, and throughout the world.

\section{Lancashire Library Service}

Lancashire Library Service in the United Kingdom was not immune to the challenges described above. Serving a population of more than 1 million people at 74 static and nine mobile libraries, Lancashire Library Service employs a staff of more than 500. Programmes offered range from traditional book-based lending services to live arts events and a provision for Lancashire Prisons. Achieving "a standard of excellence in the provision of information, learning, culture and recreational services to everyone in our local communities" is the institution's stated goal (Lancashire County Council, 2006).

A modernisation programme for libraries has seen significant investment; more than 20 libraries have been regenerated since 2008, and a new library was built in 
Heysham in 2009. The library service values the provision of information as a key function and has changed its delivery quite radically since 2008. However, funding issues have been responsible for the lack of designated reference librarians within the library service. The focus now is on channel shift and information literacy skills for library staff and service users. This has tied into a national campaign - Race Online 2012 - in the UK to enable all citizens to have the benefits of being online. It was these very goals and challenges that illustrated Lancashire Library Service's potential as a participant in Credo's information literacy pilot programme.

\section{Credo}

Credo (originally Xrefer) was established as a free site for ready reference information in 1999. Since its founding, Credo has grown to become an information skills solutions provider and library partner with offices in Oxford and Boston, Massachusetts. With well over 2,500 institutions subscribing worldwide, in 2002 the National Library of Scotland selected Credo to provide online reference to all Scottish libraries; the National Library Board of Singapore followed in July of 2003. The company's mission to promote information literacy and research effectiveness led to the launch of its nonprofit arm, Libraries Thriving, a space dedicated to communicating the value of libraries and their ability to impact the learning moment.

In 2011, recognising the growing need for information literacy support for libraries, Credo launched a pilot programme with six public and academic libraries throughout Europe and USA. Lancashire Library Service was amongst this group of libraries, and served as a collaborator to help develop a new technology platform and a suite of information literacy tools and services. Now known as Literati by Credo, this product initially served as a model for Lancashire Library Service's information literacy strategy. The collaboration encompassed a two-pronged approach, which included support for the library staff followed by the creation of materials to engage the wider community. These multimedia materials encompassed key library resources selected by Lancashire, such as Grove Art and Music Online, and NewsBank.

\section{Wide-scale staff training}

The first facet of the information literacy plan involved cultivating a strong information literacy identity amongst all Lancashire Library Service staff. The institution hoped to widen access to effective and valid sources of information, particularly as the budget cuts they faced had led to a loss of trained and experienced reference librarians. Allowing their paraprofessional staff the opportunity to gain knowledge and practise putting information literacy into use was of utmost importance after the staff transitions. This goal was achieved through professional development online webinars attended by staff at more than 80 branches, as well as council employees representing various government departments. These staff training sessions took place on three different occasions in 2012: March 22, 28, and 29. One follow-up meeting with key staff members was held on May 4, 2012 to review the training sessions, consider strengths and shortcomings of the programmes, and make plans to improve upon the 
programmes. GoToMeeting was used as the discussion venue for these sessions; the fact that staff struggled with navigating the program's technology proved to be a weakness in communication. Though Credo suggested alternative options, Lancashire determined that a portion of staff always would struggle with online webinar technology, and felt the opportunity to practise with it during these sessions provided a positive learning experience for library staff.

Early on, a culture of sharing and feedback was encouraged during the webinars to both empower staff and ensure greater "buy-in" from this group of stakeholders. Credo, similar to other library providers, already maintained the materials necessary to conduct training for its platform. However, Credo was able to work closely with Lancashire Library Service to develop learning materials that would tie information literacy into the training. Learning outcomes were developed, a script was written and revised based on these outcomes, and a simple assessment tool in the form of a survey was created to measure the achievement of the learning outcomes. This approach epitomised a "win-win" situation, as Credo was able to familiarise staff with its product, thereby increasing usage of its platform. Lancashire Library Service benefited from the time, resources, and information literacy materials that Credo was able to provide in multiple online trainings: a task that would have utilised technology, time, and support that was otherwise unavailable to Lancashire Library Service.

A 2007 survey of libraries in the USA and Canada found that less than 50 per cent of libraries with budgets of less than $\$ 1$ million were providing their staff with any type of e-learning opportunities through web conferencing software (WebJunction, 2007). Of the sample supplied by Online Computer Library Center, Inc. for the survey, 177 public libraries responded, which provided a 9 per cent response rate to the invitation. As a result, both Lancashire Library Service and Credo were glad to find that the staff feedback for the new training venture was entirely positive. In regards to the exposure to information literacy tools that could be shared with users, one staff member wrote, "It will make a refreshing change to see children using more reliable sources of information instead of Google or Wikipedia." Other staff members took advantage of the opportunity to explore information literacy topics, such as plagiarism and citation, with one specific staff member asking the webinar presenters to explain the difference between citation styles for her and her colleagues. Other techniques that were met with success included the development of handouts to suit the specific staff demographic, printable certificates of attendance, an online space where individuals could access the customised materials including recorded trainings, and an online information literacy scavenger hunt that tracked the progress of participants in achieving the learning outcomes.

\section{Information literacy materials}

Having earned "buy-in" from these stakeholders, Lancashire Library Service continued to maintain an online space for staff development while shifting its focus to the community at large. Library services were designed with information literacy learning outcomes in mind. Programmes such iTea and Biscuits and Headache-Free Tech Talks were amongst the sessions delivered to the community, and great care was taken to ensure that the materials in these sessions 
would be accessible to users unfamiliar with new technologies as well as differently abled individuals. Unlike their previous incarnations, these programmes emphasised skills such as evaluating resources, critical thinking, and responsible use of information. The programmes began with Silver Surfers in April 2010; iTea followed in September of that year, offering 11 events and drawing approximately 40 attendees. The Headache-Free Tech Talks, which began in October 2012, are comprised of 48 events and have attracted 200 attendees. These programmes are continuing in 2013. While initial numbers understandably were small, attendance has increased over time with perseverance from staff and the events have grown consistently.

Credo stepped in to create multimedia materials for extended learning opportunities, which could be accessed anytime, anywhere. Strong assessable learning outcomes were developed in the form of videos and tutorials about avoiding the pitfalls of research on the open web, evaluating primary and secondary sources, narrowing a topic, and the importance of information literacy. During an online webinar forum, librarian and staff feedback was encouraged. Individuals provided comments and suggestions via the chat box. One staff member's suggestion of a digital poster that highlights the library's databases as an answer to the drawbacks of Google searches led to the creation of a suite of posters that nurtured a growing culture of information literacy awareness. The posters include QR codes that draw users back to the institution's databases. Quick-response codes, otherwise known as QR codes, operate similarly to barcodes, though they can store a maximum of 7,089 characters, compared to the 20-digit limit of the latter (Crompton, LaFranc and van 't Hooft, 2012). Formatted as a collection of black and white pixels in the shape of a square, QR codes are scanned by dedicated apps stored on smartphones. Their presence on the posters allowed readers to access databases offered by the institution highlighted easily and immediately. The Credo-created materials were then shared at the users' point of need. By placing digital posters throughout the library and educational videos and tutorials within library databases, Credo worked to increase further the likelihood that users would put their information literacy skills into practice by accessing and evaluating reliable and trustworthy sources.

An online survey provided to librarians attempted to gather evaluations about the learning sessions. It was presented in the form of a scavenger hunt, and asked participants to use Credo's Literati tool in order to answer questions. Opportunities for short answer feedback and opinions also were provided. An additional survey, posted on Literati's website, attempted to garner comments from users and staff alike about using Literati. As a result of receiving one response from a librarian on the first survey, and zero responses to the second, Credo decided to create alternative ways of obtaining staff and user feedback through social media or more engaging formats, as opposed to surveys. This effort currently is in process.

Credo also partnered with Lancashire Library Service to promote the information literacy programming available in the libraries. Four promotional videos were made that informed users of the variety of services offered such as ebooks, "24/7 access" to library databases, fire service advice, and nurse visits. Lancashire selected a number of key resources to highlight in these videos, such as Grove Art 
and Music Online, and NewsBank. Produced by Oxford University Press, the former are digital databases allowing access to art and music reference resources. NewsBank provides library patrons with the ability to search databases containing millions of news resources, including archives. These videos not only were placed within the library's website and research platforms, but they also were uploaded to YouTube, where already they have received hundreds of views. Lancashire Library Service believes that these videos have helped open up users' eyes and put information literacy in a context that is understandable, relatable, and most importantly, attractive to users. In regards to the partnership, one Lancashire librarian commented, "Even after 40 years in libraries, it's exciting to see something so new and fresh."

\section{Information literacy initiatives}

In addition to making the most of the partnership with Credo, Lancashire Library Service participated in Race Online 2012, a UK campaign that raised digital literacy awareness and provided programming ideas and toolkits that made for a straightforward implementation of the initiative locally. The campaign sought to improve the opportunities and therefore lives of millions of UK citizens who had never been online. By tying this goal to the excitement and anticipation of the London 2012 Olympics, the campaign's organisers hoped to use the arrival of the games as a source of motivation for digital literacy advocates. Librarians from Lancashire Library Service - who had taken on the challenge of increasing the number of adult Internet users years before Race Online 2012 - joined in the momentum achieved by the initiative to ensure that adults who were digital foreigners could benefit from access to the Internet. Lancashire Library Service also was able to take advantage of the many materials that were disseminated for the Race Online 2012 campaign. This allowed the library greater time to implement programming, as much of the materials already had been created by the campaign and thereby saved Lancashire Library Service time and resources.

In order to incorporate an information literacy approach, Lancashire Library Service again partnered with Credo to create or improve Topic Pages related to the Olympics and other subjects that were relevant to the Lancashire community. Topic Pages are provided for free on the open web by Credo as a starting place for library users. They integrate librarian-approved e-books with digital-rightsmanagement-free images and library links. The Topic Pages, similar to Wikipedia pages, were developed with usability in mind to assist individuals in obtaining reliable information in a quick and convenient manner. By creating Topic Pages for subjects such as the Paralympics, Credo was able to build on the enthusiasm for the approaching Olympics while also tying in information literacy through a tool that promotes reliable information literacy skills.

\section{Conclusion}

While not all libraries may currently have a partnership with a library provider such as Credo at their disposal, there are many opportunities for collaboration in the public library sphere. First, public libraries must create an information literacy strategy that aligns with an institution's current goals and purposes in potential partners, be they library providers, community groups, or other departments in the 
government. Library providers especially are eager to establish positive relationships within the library community and often rely on libraries to pilot programmes or serve as beta testers. A public library's defined information literacy strategy allows administrators to decide if a partnership with a vendor is worth the time investment. In terms of the current study, it was clear that Literati provided highly customised training and materials responding to Lancashire's specific needs. Due to the library struggling with low staff counts, not as many multimedia materials were created as planned. Projects have been prioritised according to Lancashire's needs and the work will continue. Additionally, librarians and marketing individuals working for the Lancashire County Council alike were required to approve each project; this step created delays. Credo is in the process of developing project-specific plans to help outline goals, responsibilities, and due dates. During the next phase of the partnership, Literati will collaborate with Lancashire Library Service to provide outreach to schools as well as continue to promote the library branches.

A majority of library providers do offer trainings that serve as excellent opportunities to build in professional development time for staff. Allowing time during these training sessions for feedback will also help staff to feel heard and to be empowered to serve as information literacy advocates for change. A plethora of free information literacy online webinars also are available to staff on a wide range of topics; this only leaves library directors with the task of committing time for professional development. Similarly, the open web is becoming a growing home to information literacy videos and tutorials that can be shared amongst users to promote the tenets of information literacy, saving time for public libraries unable to create their own resources. These multimedia materials can also aid in reaching a larger library audience and therefore increase the return on investment for the time librarians contribute to promoting information literacy. Around the world, information literacy initiatives impacting the public library sphere are being launched or finding success as they develop (Špiranec and Pejova, 2010; Virkus, 2003). Turning to government-led initiatives or other local and national campaigns can help libraries construct the backbone of their information literacy strategies, which can then thrive through thoughtful partnerships.

\section{References}

Bawden, D. and Robinson, L. (2009) The dark side of information: overload, anxiety and other paradoxes and pathologies, Journal of Information Science, 35(2), 180-191.

Collins, K. L. K. and Takacs, S. N. (1993) Information technology and the teaching role of the college librarian, The Reference Librarian, 18(39), 41-51.

Crompton, H., LaFrance, J. and van 't Hooft, M. (2012) QR Codes 101, Learning \& Leading with Technology, 39(8), 22-25.

Demasson, A. E., Partridge, H. L. and Bruce, C. S. (2010) How do public librarians constitute information literacy? Proceedings of the fifth international 
conference on qualitative research in IT \& IT in qualitative research, 29-30 November 2010. URL: http://eprints.qut.edu.au/39896/ [accessed 06.05.13].

Eisenberg, M. B. (2010) Information literacy: essential skills for the information age, DESIDOC Journal of Library \& Information Technology, 28(2), 39-47.

Elmborg, J. (2006) Critical information literacy: implications for instructional practice, The Journal of Academic Librarianship, 32(2), 192-199.

Harding, J. (2008) Information literacy and the public library: we've talked the talk, but are we walking the walk, Australian Library Journal, 57(3), 274-294.

Heidi, J. and Hoffman, C. (2008) Information literacy training in Canada's public libraries, The Library Quarterly, 78(1), 19-41.

Jacobs, H. M. L. (2008) Information literacy and reflective pedagogical praxis, The Journal of Academic Librarianship, 34(3), 256-262.

Kapitzke, C. (2003) Information literacy: a review and poststructural critique, Australian Journal of Language and Literacy, 26(1), 53-66.

Lancashire County Council (2006) Library and information service: service development plan 2007-2010. URL:

http://www.lancashire.gov.uk/libraries/borrower/0507Service\%20plan\%2020072010.pdf [accessed 17.1.13].

Probert, E. (2009) Information literacy skills: teacher understandings and practice, Computers \& Education, 53(1), 24-33.

Rader, H. B. (2002) Information literacy 1973-2002: a selected literature review, Library Trends, 51(2), 242-259.

Špiranec, S. and Pejova, Z. (2010) Information literacy in South-East Europe: formulating strategic initiatives, making reforms and introducing best practices, The International Information \& Library Review 42(2), 75-83.

Špiranec, S. and Zorica, M. B. (2010) Information Literacy 2.0: hype or discourse refinement?, Journal of Documentation 66(1), 140-153.

Sze, L. (2012) Innovations during the e-book era, Public Libraries, 51(1), 13.

Thomas, S. et al. (2007) Transliteracy: crossing divides, First Mondays [online], 12(2). URL:

http://firstmonday.org/htbin/cgiwrap/bin/ojs/index.php/fm/article/view/2060/1908 [accessed 17.1.13].

Virkus, S. (2003) Information literacy in Europe: a literature review, Information Research, 8(4). URL: http://informationr.net/ir/8-4/paper159.html [accessed 06.05.13].

WebJunction (2007) Staff training in public libraries: 2007 fact sheet. URL: http://www.webjunction.org/content/dam/WebJunction/Documents/webjunction/S taff-Training-in-Public-Libraries-2007-Fact-Sheets.pdf [accessed 17.1.13].

Zhang, X., Majid, S. and Foo, S. (2010) Environmental scanning: an application of information literacy skills at the workplace, Journal of Information Science 36(6), 719-732. 


\section{Open access and copyright}

Library and Information Research is an open access journal. A freely available copy of this paper may be downloaded from the journal's website: http://www.cilipjournals.org.uk/lir

Copyright and associated moral rights in works published in Library and Information Research are retained by the author(s) but this paper may be used freely, with proper attribution, in educational and other non-commercial settings. 